\title{
Enterprise Core Technology Breakthrough Mechanism From the Perspective of Innovation Ecosystem Taking Huawei Baseband Chip Technology as An Example
}

\author{
Li Zhenjie ${ }^{1, *}$ Xiang Guopeng ${ }^{2}$ \\ ${ }^{1}$ School of Business Administration, School of Tourism and Urban and Rural Planning, Zhejiang Gongshang University, \\ Hangzhou 310018, China \\ ${ }^{2}$ School of Tourism and Urban and Rural Planning, Zhejiang Gongshang University, Hangzhou 310018, China \\ *Corresponding author. Email: 1300218634@qq.com
}

\begin{abstract}
The lack of core technology is the pain point and difficulty of the development of enterprises in China. How to realize the breakthrough of core technology is an important problem to be solved urgently. Based on the understanding that the core technology breakthrough is the requirement of the construction and operation mechanism of enterprise innovation ecosystem, this study explores the breakthrough mechanism of enterprise core technology from the perspective of innovation ecosystem. It also makes a longitudinal case study on the technical breakthrough process of Huawei baseband chip. The research shows that Huawei innovation ecosystem provides support for Huawei's core technological breakthrough through its two operating mechanisms of opening and sharing, concurrence and symbiosis. Finally, it realizes the technical breakthrough of baseband chip from general non-core component technology to general core component technology to product integration and optimization. This study provides practical enlightenment for the core technological breakthrough of enterprises from the perspective of innovation ecosystem.
\end{abstract}

Keywords: core technology, innovation ecosystem, openness and sharing, concurrence and symbiosis

\section{INTRODUCTION}

The occurrence of the ZTE incident has exposed the grim reality of China's lack of core technology, which makes it an urgent and important task for Chinese enterprises to carry out independent innovation and break through the core technology. Core technological innovation is often difficult to be completed by an enterprise alone, and multiple agents need to cooperate in order to complete the core technological innovation of a product or even a component. Therefore, the breakthrough of core technological competence is not only a test of enterprise innovation ability, but also a test of enterprise innovation ecosystem. Huawei has gone from following in the $2 \mathrm{G}$ era, keeping pace with the $3 \mathrm{G}$ era and leading in the $4 \mathrm{G}$ era, until $5 \mathrm{G}$ is far ahead in the world, which shows Huawei's core technological breakthrough. Most of the existing researches study the core technological breakthroughs of enterprises from the perspectives of patent, strategy, structural innovation and organizational learning. Few scholars discuss the effect of the construction and operation mechanism of innovation ecosystem on enterprise core technological breakthrough from the perspective of innovation ecosystem, so this study studies the core technology breakthrough mechanism of enterprises from the perspective of innovation ecosystem, and takes Huawei as a case study. It not only provides reference and inspiration for Chinese enterprises' core technology breakthrough, but also provides a new theoretical perspective for the existing research on enterprise core technology breakthrough.

\section{RELATED THEORY}

\subsection{Enterprise innovation ecosystem}

\subsubsection{Connotation of enterprise innovation ecosystem}

The enterprise innovation ecosystem was clearly put
forward by Adner [1]. He believes that enterprises should
put innovation at the core, and at the same time,
enterprises need to build a complete innovation chain with
relevant partners to promote the success of innovation [2].
Zhang Yunsheng [3] defines the innovation ecosystem as
an innovation system based on component / module
knowledge alienation, symbiosis and co-evolution formed
by high-tech enterprises all over the world. The innovation
ecosystem is composed of multi-agents, including large
enterprises, small and medium-sized enterprises, start-ups, 
service institutions, investment institutions, government departments, scientific research institutions and so on [45]. The relative balance of the ecosystem is maintained by competitive cooperation among agents [6-7]. At the same time, different subjects can be divided into three population of research, development and application [8].

\subsubsection{The operating mechanism of innovation ecosystem}

Scholars mainly study the operation mechanism of innovation ecosystem from the perspectives of opening [9$10]$, sharing [2], niche decision [9,11], symbiosis [9,12], learning [13], diffusion and access [10], coordination [14$15]$, catalysis and emergence [2,16]. It is considered that the innovation ecosystem is an organic and unified whole that formed by the interaction of the innovation subject and its innovation environment. Based on the common will and goal, the innovation subjects in the system integrate the innovation resources in the ecology by means of openness and cooperation to build a win-win innovation network, and make use of their respective strengths to benefit each other and learn from each other. to achieve symbiosis, sharing, co-creation and win-win. At the same time, there is a multi-agent competition and cooperation relationship in the innovation ecosystem, innovation subjects should not only pay attention to their own internal innovation behavior, but also need to consider the effective coordination and integration with other innovation subjects. These mechanisms play an important role in the operation of the innovation ecosystem. Agents share resources through open mechanisms, and then deal with the relationship of competition and cooperation among agents through mechanisms such as niche decisionmaking. In order to promote mutual learning between agents, resource diffusion and acquisition, and finally achieve the catalysis and emergence of innovative achievements, achieve coordination and symbiosis among subjects, and achieve the goal of win-win. It can be said that the core operating mechanism of innovation ecosystem is opening and sharing as well as concurrence and symbiosis mechanism. Therefore, this study mainly discusses the operating mechanism of innovation ecosystem from the two mechanisms of opening and sharing, concurrence and symbiosis.

The opening and sharing mechanism of innovation ecosystem means that enterprises make full use of internal and external resources to carry out technological development and innovation activities, and commercialize technological achievements through internal and external channels [17]. A complete opening and sharing mechanism should include at least three elements: innovation subject, innovation resources and open innovation platform. Through multi-party participation, interaction and cooperation and sharing of innovation subjects, we should establish an open innovation platform that effectively combines the internal innovation requirements of the innovation subject with its external innovation resources [2]. This platform is an important carrier for bringing together innovation resources, capital and talents [18]. The innovation network formed between subjects can realize the rapid flow and sharing of innovation resources. The internal innovation platform built within the enterprise can enhance the technology management ability of the enterprise, facilitate the identification of innovation value, obtain and absorb external technology resources, and through a flexible intellectual property management model, ensure the maximization of innovation performance [19]. At the same time, enterprises can also strengthen their independent innovation, cultivate absorptive capacity, and promote the implementation of open innovation by actively integrating into technology alliances, seeking technology outsourcing and cultivating core technical talents [20].

The concurrence of innovation ecosystem means that there must be a concurrence relationship between innovation subjects in innovation ecosystem, and this relationship will change with the change of niche relationship among innovation subjects [2,21]. Symbiosis is common in the behavior of enterprise subjects, such as technological innovation, knowledge sharing, product exchange and learning path [22], which generally includes three modes: resource sharing mode, resource overlap mode and resource separation mode [23]. The competitioncooperation symbiosis mechanism of innovation ecosystem consists of four elements, namely, competitioncooperation symbiosis unit, competition-cooperation symbiosis platform, competition-cooperation symbiosis interface and competition-cooperation symbiosis network, which operate under the common environmental background. The competition-cooperation symbiosis unit is the main body participating in innovation, the competition-cooperation symbiosis platform is the collection of many competition-cooperation symbiosis units, the competition-cooperation symbiosis interface is the sum of the interaction of competition-cooperation symbiosis units, and the competition-cooperation symbiosis network is the relationship between competition and cooperation symbiosis units. It evolves along the path of "unit-platform-interface-network". Based on the degree of similarity of the niche of competing and coexisting symbiotic units in the innovation chain, it can be divided into similar units and heterogeneous units, and this concept is relative and will change according to the niche of the subject in different innovation chains. The symbiotic relationship between similar units is more competitive, while the symbiotic relationship between heterogeneous units is more labor division. Therefore, it has evolved two different paths: the symbiotic path of division of labor and cooperation and the development path of competitive and cooperative symbiosis [2].

\subsection{Core technology}

Scholars often understand the connotation of core technology from the perspective of product or knowledge [24-25] . Ma Junru [26] believes that the core technology 
refers to one or more technologies in which similar products in a certain industry or field play the most critical role in the market competition. Wang Jiang [27] proposed that the core technology is represented by different forms of knowledge such as patents, know-how and industrial standards. Gao Qiaozi [28] believes that the core technology is the key or basic technology of the product, the unique and irreplaceable technology that is difficult for competitors to imitate, and the basis for improving the competitiveness of products. Based on the above research, this study defines the core technology as the technology that the enterprise has independent intellectual property rights, is the most important to support the sustainable development of its industry, and is difficult to imitate. Scholars mostly divide the structure of core technology from the aspects of module, link and micro-mechanism. Fu Yuwu divides the automobile core technology into six modules such as whole vehicle development technology and chassis technology [29]. Hong Yong and Su Jingqin [30] divided the core technology into three links: key manufacturing technology, core component technology and product architecture technology. Li Xianjun and Meng Donghui [31] think that the core technology is composed of principle core technology, performance core technology and reliability core technology. This study believes that the core technology is composed of a variety of technologies, enterprises to master a variety of technologies is not achieved overnight, but by mastering all the technologies contained in the core technology, so as to finally complete the core technology breakthrough. Therefore, this study divides the core technology into three parts: general noncore component technology, general core component technology and product integration and optimization according to its importance, versatility and whether it is crossed with other products.

The existing core technology research is mainly based on the theories of innovation catch-up, capability, network, evolution, etc., from the perspectives of patent [32], architecture innovation [33], strategy [34-35], organizational learning sequence $[31,36]$, etc. the breakthrough process of core technology is studied, and how to develop and improve the core competence of enterprises is discussed. It is considered that emerging technology, architecture innovation, product modularization and niche strategy can provide enterprises with opportunities to catch up, subvert and reconstruct the industrial pattern, guide R \& D investment, and reduce the pressure of competition. There are few studies on the mechanism of the construction and operation of enterprise innovation ecosystem on the breakthrough of enterprise core technology from the perspective of innovation ecosystem. However, the complexity of core technology and the development trend of enterprises through the construction of ecosystem make it very necessary to explore the breakthrough process of enterprise core technology from the perspective of innovation ecosystem. This is of great significance for a more in-depth and comprehensive analysis of the breakthrough mechanism of the enterprise's core technology and putting forward practical suggestions for the enterprise. Therefore, this paper chooses to explore the mechanism of innovation ecosystem on the core technological breakthrough of enterprises from the perspective of innovation ecosystem.

\section{METHODS AND OBJECTS}

\subsection{Method}

This study uses the method of longitudinal single case analysis. The reasons are as follows. First of all, there is very little literature to explore the process of core technological breakthrough from the perspective of innovation ecosystem, and it is difficult for existing theories to fully reveal its internal mechanism. The case study is applicable to the phenomenon that the existing theory is not suitable to explain or the explanation is insufficient [37-38]. In addition, the single case study is suitable for the study of representative typical cases, especially the longitudinal study of the same case based on a long-term process-oriented perspective, which is helpful to confirm the sequence of key events and identify causality [39-40]. The breakthrough of core technology is often a long-term and complex process. This paper is to explore the promotion process of core technology by the development of innovation ecosystem in this process. The vertical single case method is very consistent with the purpose of this study [41].

\subsection{Sample}

Following the principle of theoretical sampling, through the analysis and screening of case materials, we finally choose Huawei Technology Co., Ltd. (hereinafter referred to as Huawei) in the terminal field of the core technology baseband chip breakthrough as a typical case to conduct an in-depth vertical single case study, the reasons are as follows: first, theoretical adaptation. Huawei is a pioneer and model for domestic enterprises to achieve core technological breakthroughs through the establishment of an innovation ecosystem. Huawei promotes innovation capabilities by building an innovation ecosystem. The model of achieving core technological breakthroughs has always been the focus of the industry and academia $[33,42-43]$. Second, the typicality of the case. Huawei is the most competitive Chinese company in the global communications industry, starting research and development of baseband processors in 2007, launching Barone 700 in 2010, successfully breaking Qualcomm monopoly, and then releasing Barone 5000 in 2019, taking the lead in completing $5 \mathrm{G}$ technology breakthroughs. From the initial key technology is controlled by people, to finally stand at the forefront of the world technology, the breakthrough of Huawei baseband chip technology 
provides a very typical research sample for this paper. Third, data availability. This paper mainly uses the second-hand data research method. Huawei, as an international well-known company, has sufficient literature for reference, which provides the necessary data for this study.

\subsection{Data collection}

This paper uses second-hand data for research. Su Jingqin and Liu Jing [44] believe that under the condition that rich second-hand data can provide effective support for case studies, case researchers can conduct case studies based on second-hand data. In order to ensure the authenticity and reliability of the case study, this paper selects a variety of sources of data, including relevant books, periodical papers, patent data and the official websites of relevant subjects such as corporate websites, research institutions and colleges and universities. And these information verify each other to ensure its authenticity, and finally summarized into a group of official materials to form a complete context of development (Table 1).

Table 1 case data sources

\begin{tabular}{|c|c|c|c|}
\hline Data type & Source & $\begin{array}{c}\text { Quantit } \\
\mathbf{y}\end{array}$ & Main contents \\
\hline $\begin{array}{l}\text { Official } \\
\text { information }\end{array}$ & $\begin{array}{l}\text { Official website and official } \\
\text { Weibo }\end{array}$ & 7 & $\begin{array}{c}\text { Relevant information released on Huawei's official } \\
\text { website and the official Weibo, the official websites } \\
\text { of universities and research institutions }\end{array}$ \\
\hline Book & Library & 8 & Books related to the development of Huawei \\
\hline $\begin{array}{l}\text { Periodical } \\
\text { papers }\end{array}$ & $\begin{array}{l}\text { CNKI, VIP, Wanfang, Web } \\
\text { of Science and other } \\
\text { websites }\end{array}$ & 64 & $\begin{array}{c}\text { The key words of periodical search are Huawei } \\
\text { technology, Huawei core technology, Huawei } \\
\text { patent, Huawei innovation, Huawei baseband, } \\
\text { Huawei R \& D and so on. }\end{array}$ \\
\hline News & $\begin{array}{l}\text { Search engines such as } \\
\text { Baidu and Google }\end{array}$ & 27 & $\begin{array}{c}\text { Search with Huawei baseband, Huawei chip, } \\
\text { Huawei Barone chip, Huawei Kirin chip, Huawei R } \\
\text { \& D, etc. }\end{array}$ \\
\hline Patent data & $\begin{array}{l}\text { International intellectual } \\
\text { property Organization Patent } \\
\text { Database and Chinese } \\
\text { National Patent Database }\end{array}$ & 2 & $\begin{array}{c}\text { Patent Information of all related components of } \\
\text { Huawei Baseband Chip }\end{array}$ \\
\hline
\end{tabular}

\section{CASE DESCRIPTION [46-53]}

Huawei was founded in 1987 in Shenzhen, Guangdong Province, initially as a subscriber exchange sales agent. In 1990, Huawei began its own research and development and became a communications equipment manufacturer with both manufacturing and sales. Huawei's mobile terminal business is the main business direction of Huawei consumer business, which has released a series of products, such as $\mathrm{P}$, Mate, nova, Mai Mang, Changxiang and so on. Huawei has made great achievements in the technological innovation of baseband chips. Since the release of Barone 710 in 2010, Huawei has successively released a series of baseband chips, such as Barong 710, Qilin 710, Barong 720, Kirin 920, Qilin 960, Kirin 980, Barone 5000, etc., completing the leap from following to taking the lead. The baseband chip is the core component of the mobile phone, which is used to synthesize the baseband signal that is about to be transmitted or to decode the received baseband signal. It is composed of CPU processor, channel codec, digital signal processor, modem and interface module [45]. These modules require enterprises to have many different technologies and knowledge (figure 1). 


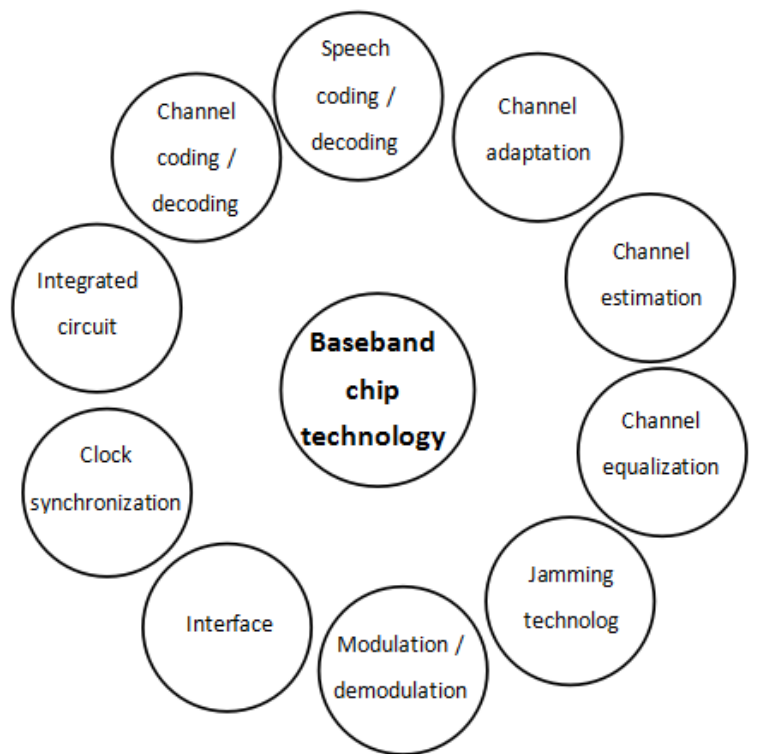

Figure 1 main technical composition of baseband chip

The acquisition of core technology of Huawei baseband chip has gone through three stages.

The first stage is the stage of perfecting the internal R \& D system (1987-1998). Huawei is first involved in the field of $\mathrm{R} \& \mathrm{D}$, establishing and perfecting the internal $\mathrm{R} \& \mathrm{D}$ system and making use of innovation resources in various parts of the country. Through the integration of internal resources [54], the expansion of the relationship between major external partners, and the interaction and coordination of internal management departments [55], the internal innovation ecosystem is established, which lays a good foundation for the outward expansion of Huawei innovation ecosystem. At this stage, Huawei is equipped with general non-core component technologies for baseband chips, such as voice codec, clock synchronization, interface, integrated circuit and so on (figure 2).

The second stage is the international R \& D layout stage (1999-2006). Huawei has shifted from the original construction of internal innovation ecosystem to peer-topeer cooperative innovation, through the participation of leading users [56], the development of governmentindustry-school cooperation [57], the construction of customer-supplier relationship network[58-59], etc., to build a simple innovation ecosystem. Huawei has the general core component technology of baseband chip, such as channel coding / decoding, channel adaptation, channel estimation, channel equalization, interference technology, modulation / demodulation and so on.

The third stage is the core technology breakthrough and rapid iteration stage (2007-present). On the basis of the original industry-university-research cooperation, Huawei has carried out collaborative innovation for the government, enterprises, universities, scientific research institutions, intermediary organizations, financial institutions and other main bodies [60-61]. By establishing research institutes, laboratories, and open source communities in joint innovation, Huawei continues to expand its innovation ecosystem and create more innovation achievements. At this stage, Huawei successfully realized the product integration of each component technology of Huawei baseband chip and carried out a rapid iterative upgrade.

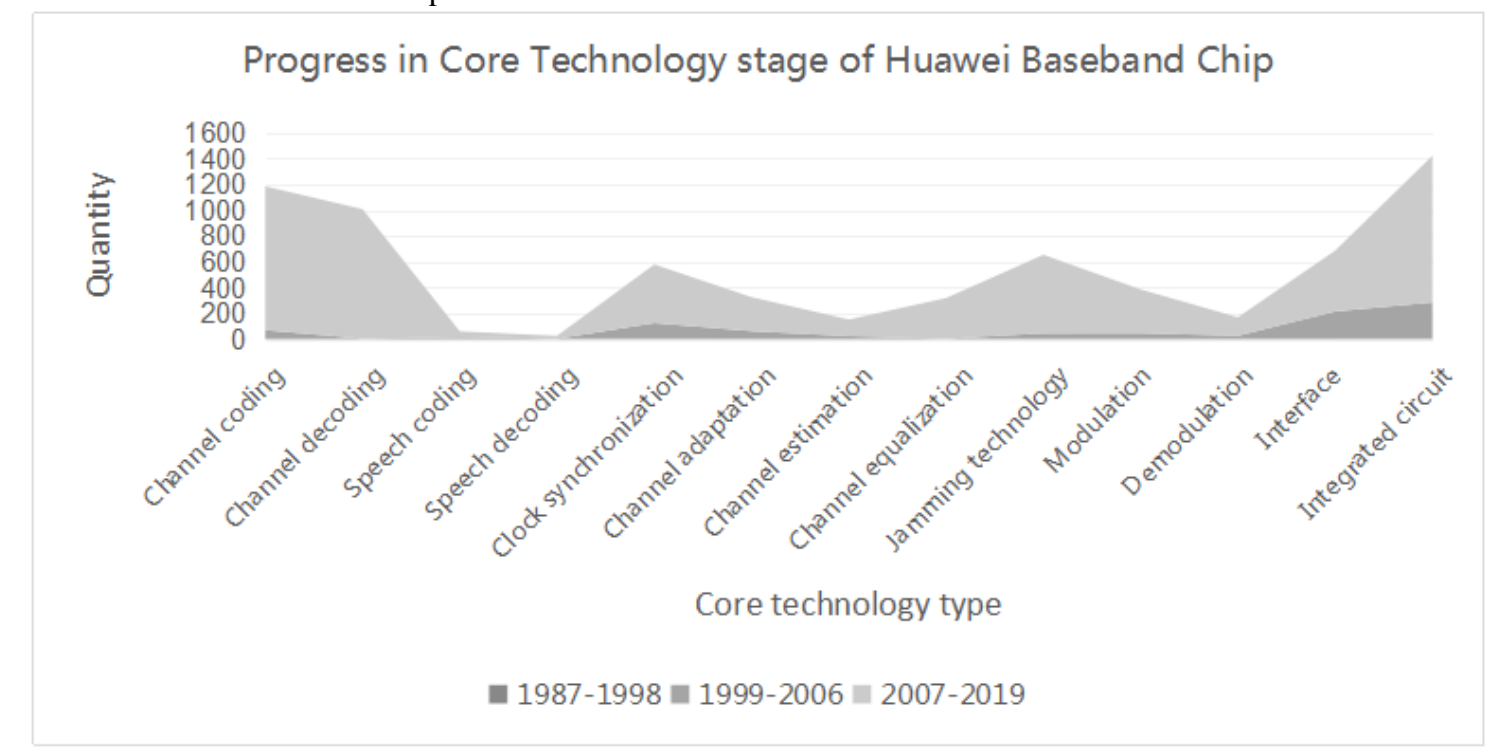

Figure 2 Progress of baseband chip technology 


\section{CASE ANALYSIS}

\subsection{Improvement stage of internal $R \& D$ system (1987-1998)}

The innovation main body of Huawei's innovation ecosystem at this stage is mainly composed of Huawei, cooperative enterprises, joint venture companies, scientific research institutions, universities and customers. Among them, universities and research institutes jointly form the research community of Huawei innovation ecosystem, the development population is composed of Huawei, component suppliers and processing enterprises, and the application group is composed of cooperative enterprises, joint ventures and customers. The research direction is determined by the market and demand information transmitted by customers, cooperative enterprises, joint ventures, etc., and then through the internal support system of Huawei Planning Office, General Office, cadre Department, etc., through the support of talents, funds, knowledge, information and other resources for Huawei's central research department, in order to support Huawei's research and development, and through cooperation with component suppliers and processing enterprises to produce corresponding products.Finally, the products are distributed to users through Huawei, joint ventures and joint ventures (figure 3 ).

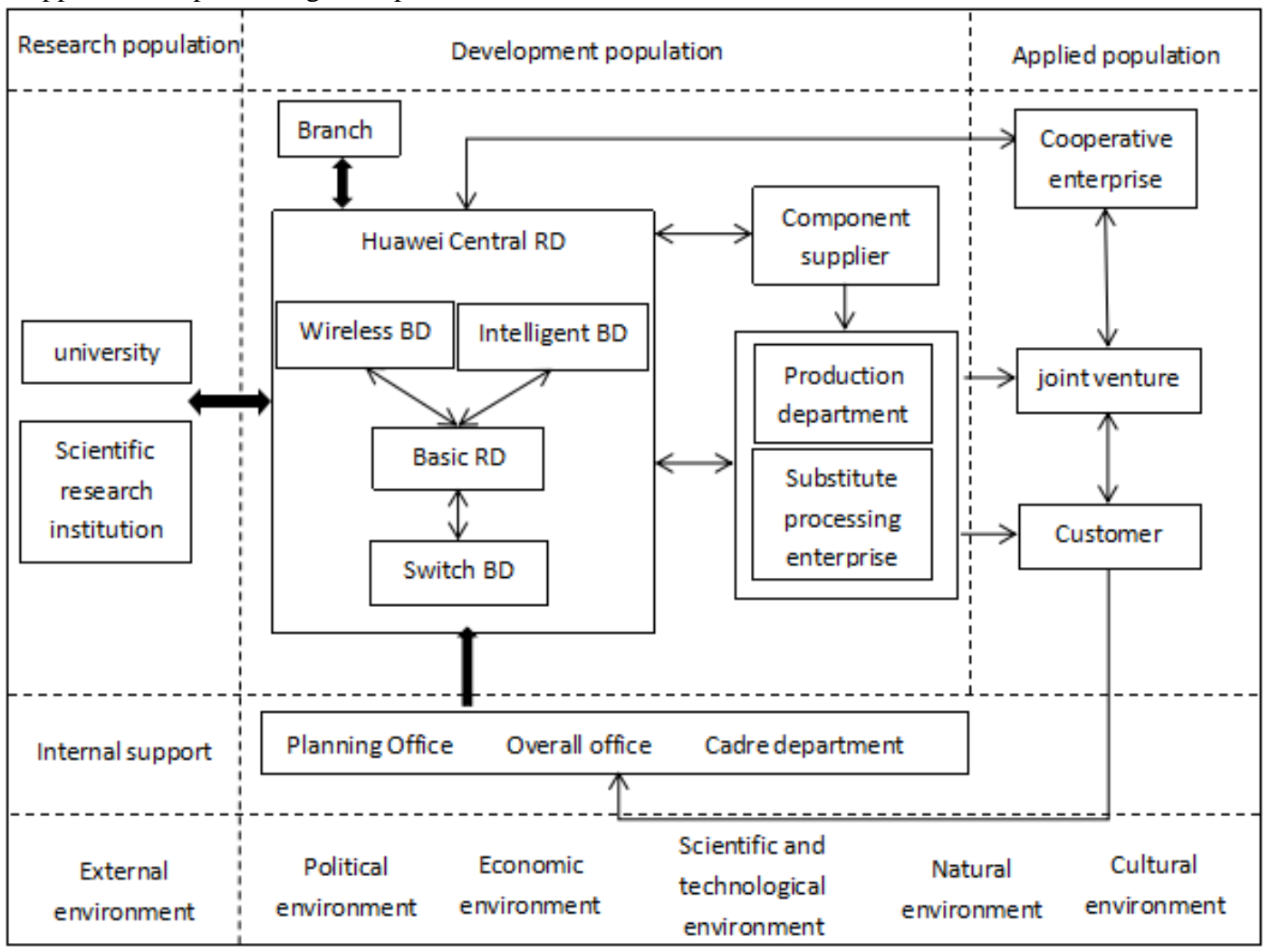

Figure 3 Innovation ecosystem in the stage of perfection of Huawei's internal R \& D system

Note: RD: Research department ; BD: Business department

Huawei innovation ecosystem has established an open and sharing mechanism with Huawei, component suppliers, scientific research institutions, universities, cooperative enterprises and customers as the main body, the internal intellectual property management system and the open innovation culture and external open innovation platform promote each other, in order to establish various types of competition and cooperation symbiosis mechanism with heterogeneous units (figure 4).

Huawei has established a simple external innovation network by cooperating with domestic and foreign enterprises or establishing joint ventures, establishing research institutes or branches to conduct cooperative research and development with domestic universities, and signing talent training agreements to establish an open innovation platform. And through the external innovation network to exchange and share innovation resources with various subjects, gather innovation resources and accelerate the flow of resources; through cooperative R \& $\mathrm{D}$, both sides share innovation costs and risks, reduce the occupation of resources, cost investment and R \& D risks, and greatly improve the R \& D efficiency of enterprises. In addition, Huawei has successively set up the Central Research Department and the intellectual property Department to manage intellectual property rights, ensuring the timely patenting and standardization of knowledge and technological achievements, and strengthening the protection and utilization of its own intellectual property rights. Then, establish an open and innovative corporate culture within the enterprise, treat 
and integrate all kinds of resources of the industry with an open mind, which lays an ideological foundation for Huawei's open innovation.

Huawei has established a labor-division and cooperative symbiosis relationship with other units by establishing a competitive and cooperative symbiosis platform dominated by enterprise cooperation and joint ventures, as well as cooperative research and development with universities and scientific research institutions. Due to the low degree of trust among the subjects, the symbiosis mode between the units is mainly the resource separation mode, and the resources mainly exist outside the units and circulate through the competing symbiosis platform.



Figure 4 operational mechanism of innovation ecosystem in the stage of perfection of Huawei's internal R \& D system

Thanks to the role of Huawei's innovation ecosystem opening and sharing, competition and symbiosis mechanism in gathering innovative resources, accelerating the flow of resources, reducing $\mathrm{R} \& \mathrm{D}$ costs and risks, improving $\mathrm{R} \& \mathrm{D}$ efficiency, and building a harmonious development environment, Huawei successfully mastered voice codec, interface control, clock synchronization technology, integrated circuits and other technologies, and completed a breakthrough in general non-core component technology for baseband chips.

\subsection{International $R$ \& D layout stage (2000- 2006)}

At this stage, Huawei's innovation ecosystem is mainly composed of suppliers, Huawei, operators, universities, competitors, scientific research institutions, government, users and so on (figure 5). Among them, the research community is composed of universities and research institutions, the development community is composed of Huawei, suppliers, competitors and operators, and the application group is composed of operators and users, which are not only the users of Huawei products, but also provide new ideas and suggestions for the product innovation of Huawei products, and promote the optimization and improvement of Huawei products. Internally, Huawei carries out R \& D system reform by introducing management systems such as IPD integrated product development, so as to bring Huawei's internal R \& D system in line with international standards and support Huawei's international R \& D process. Externally, through the establishment of research institutes and branches in various parts of the country, cooperative research and development with domestic enterprises and universities, and signing talent training agreements, domestic resources are integrated. Through the establishment of research institutes in countries around the world, cooperation with universities around the world to establish network 
colleges, cooperation with advanced enterprises in the world to carry out authorized training for talent internationalization, to provide Huawei with sufficient and high-quality human resources for innovation. Through technical cooperation with suppliers, competitors, operators and other innovation entities, establishing joint ventures, technology $R$ \& $D$ platforms, joint $R$ \& $D$ laboratories, joint innovation centers and other innovation platforms to carry out international R \& D, while users are also involved, to provide innovative inspiration and suggestions for Huawei innovation. The participation of the government, industrial alliances and standards organizations in the innovation ecosystem provides environmental support for Huawei's innovation and provides protection for Huawei's intellectual property rights.

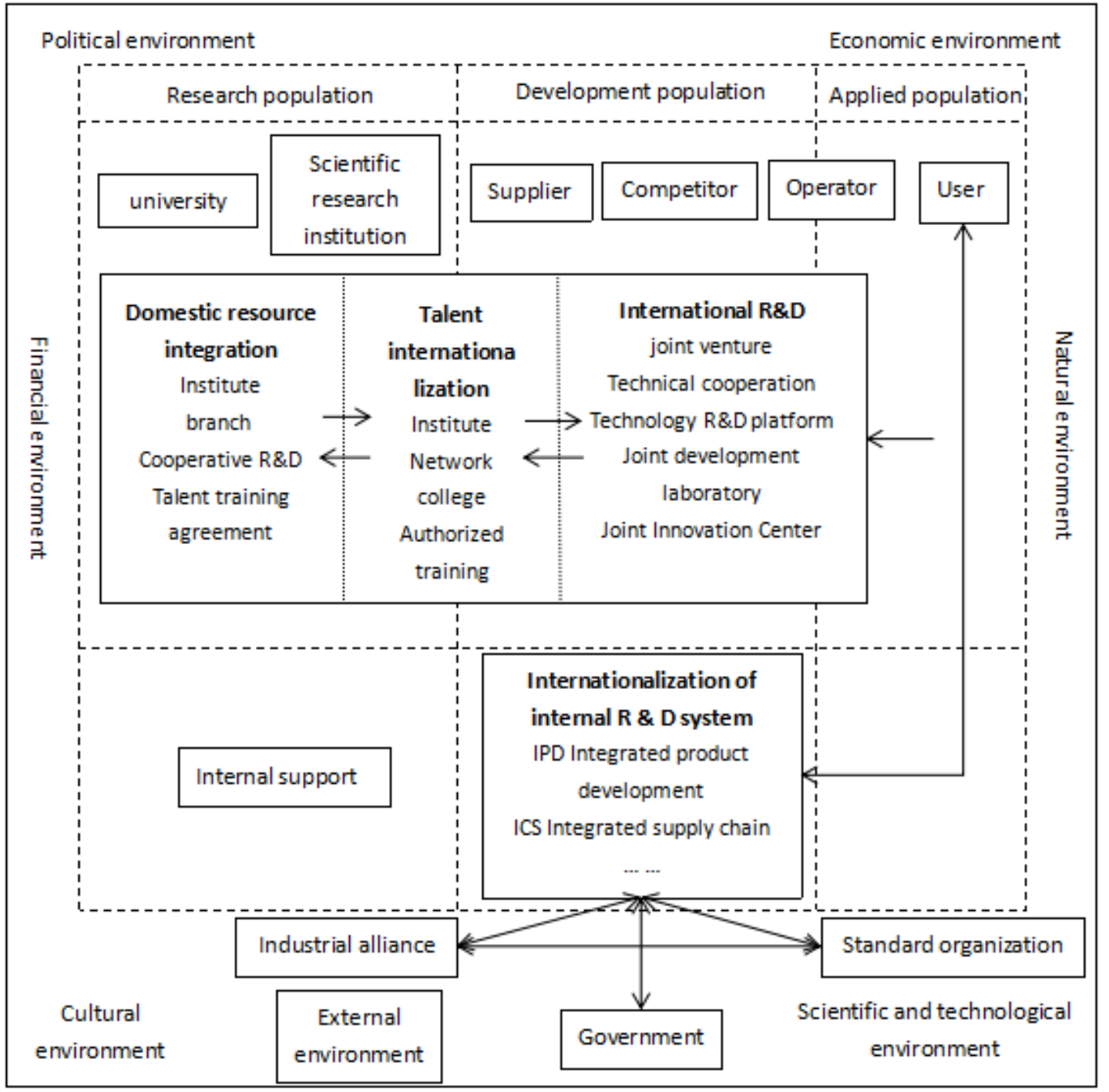

Figure 5 Innovation ecosystem in Huawei's international R \& D layout stage

In the stage of international $\mathrm{R} \& \mathrm{D}$ layout, Huawei has established an open and sharing mechanism with Huawei, operators, users, suppliers, competitors, universities, scientific research institutions, standards organizations, and industrial alliances as the main innovation subjects, internal open innovation corporate culture, internal resource sharing mechanism and internal innovation platform promote and coordinate each other and support the operation of Huawei's external open innovation platform. And through the establishment of a variety of types of competing and cooperative symbiotic interface to maintain the competitive and cooperative symbiotic mechanism with similar units based on competing and cooperative development, and with different units based on division of labor and cooperation (figure 6).

Internally, Huawei has carried out internal R \& D system reform, established an internal innovation platform based on IPD integrated product $\mathrm{R} \& \mathrm{D}$ process system, to adapt to the trend of openness and sharing; established an internal resource sharing mechanism to promote the sharing and utilization of innovation resources; and together with Huawei's open innovation culture, provided basic support for the operation of Huawei's innovation ecosystem. Externally, Huawei has established various 
types of open innovation platforms with competitors, suppliers and operators to carry out cooperative research and development of products and technologies, and share innovation resources. And through participation in international standards organizations and industrial alliances, information exchange and sharing, actively integrate into the innovative environment; through cooperation with domestic and foreign enterprises to carry out authorized training or the establishment of training centers, the two sides share staff training experience and jointly train high-skilled applied talents. Through the establishment of research institutes around the world and cooperative research and development with universities at home and abroad, signing talent transfer agreements, and cooperating in the establishment of network colleges, we can share talents, knowledge and technology, and jointly train professionals.
For the long-term development of the enterprise, Huawei adopts the international strategy of open cooperation, follows the principle of extensive cooperation [52], and establishes a long-term strategic relationship with its competitors. By establishing a joint venture company, signing a patent cross-license agreement, establishing a joint R \& D center and an open laboratory, the two sides establish a competitive and cooperative symbiotic relationship based on resource separation mode and resource sharing mode. While Huawei and suppliers, operators, scientific research institutions, universities, users and other heterogeneous units through the establishment of joint ventures, joint innovation centers, network colleges, open laboratories, open innovation platforms and other forms of competitive and cooperative symbiotic interface to establish a division of labor and cooperation based on resource separation mode and resource sharing mode.

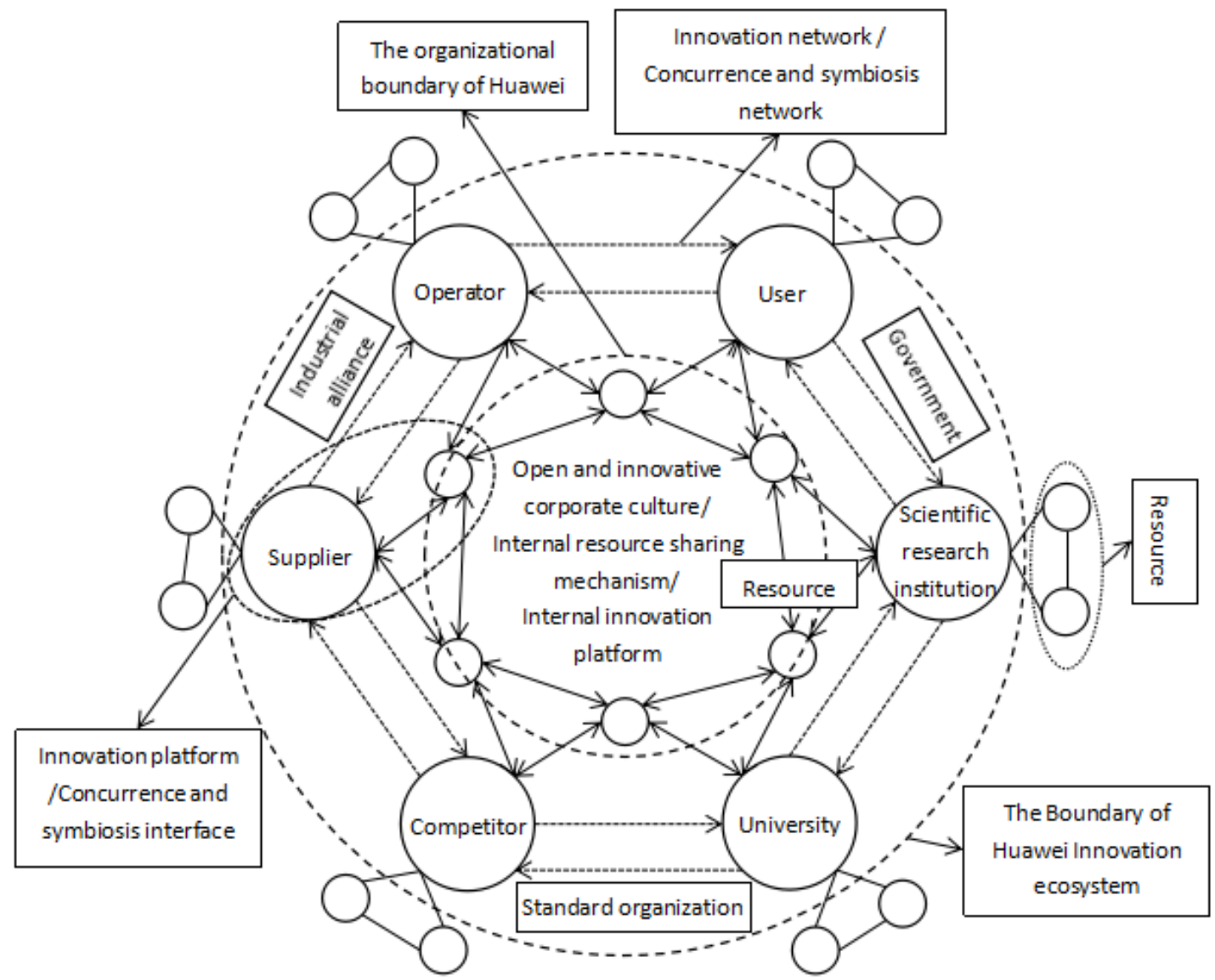

Figure 6 operating mechanism of innovation ecosystem in Huawei's international R \& D layout stage

Through these two mechanisms, Huawei innovation ecosystem gathers a large number of innovation resources for its baseband chip technology breakthrough, accelerates the flow of innovation resources, improves the utilization efficiency of innovation resources, builds a more harmonious external environment for Huawei innovation and development, reduces Huawei R \& D risks and costs, improves Huawei R \& D efficiency, and enables Huawei to obtain a large number of innovation achievements in various composition technologies of baseband chips. All kinds of technologies have made a breakthrough, and successfully completed the breakthrough of the general core module technology of baseband chip. 


\subsection{Core Technology Breakthrough and Fast iteration stage (2007-2019)}

At this stage, Huawei's innovation ecosystem is mainly composed of suppliers, competitors, operators, other enterprises, Huawei, universities, scientific research institutions, government, users, industrial alliances, standards organizations, open source communities and intermediary institutions. Among them, the research community is composed of universities and research institutes. In addition to Huawei, suppliers, competitors and operators, users also begin to directly participate in Huawei's product research and development process and become a member of its development community, while the application community is also composed of operators and users (figure 7). The government, together with other enterprises and intermediaries, provides Huawei with policy support and good services for innovation, which has become the external support for Huawei's innovation. On the other hand, innovative subjects such as scientific research institutions, universities, suppliers, operators, competitors and users, together with Huawei's internal R \& $\mathrm{D}$, jointly carry out personnel training, collaborative R \& $\mathrm{D}$ and establish international technical standards through a variety of ways. At the same time, Huawei actively participates in international standard-setting and tracks technological frontiers by joining international organizations such as open source communities, standards organizations and industry alliances.

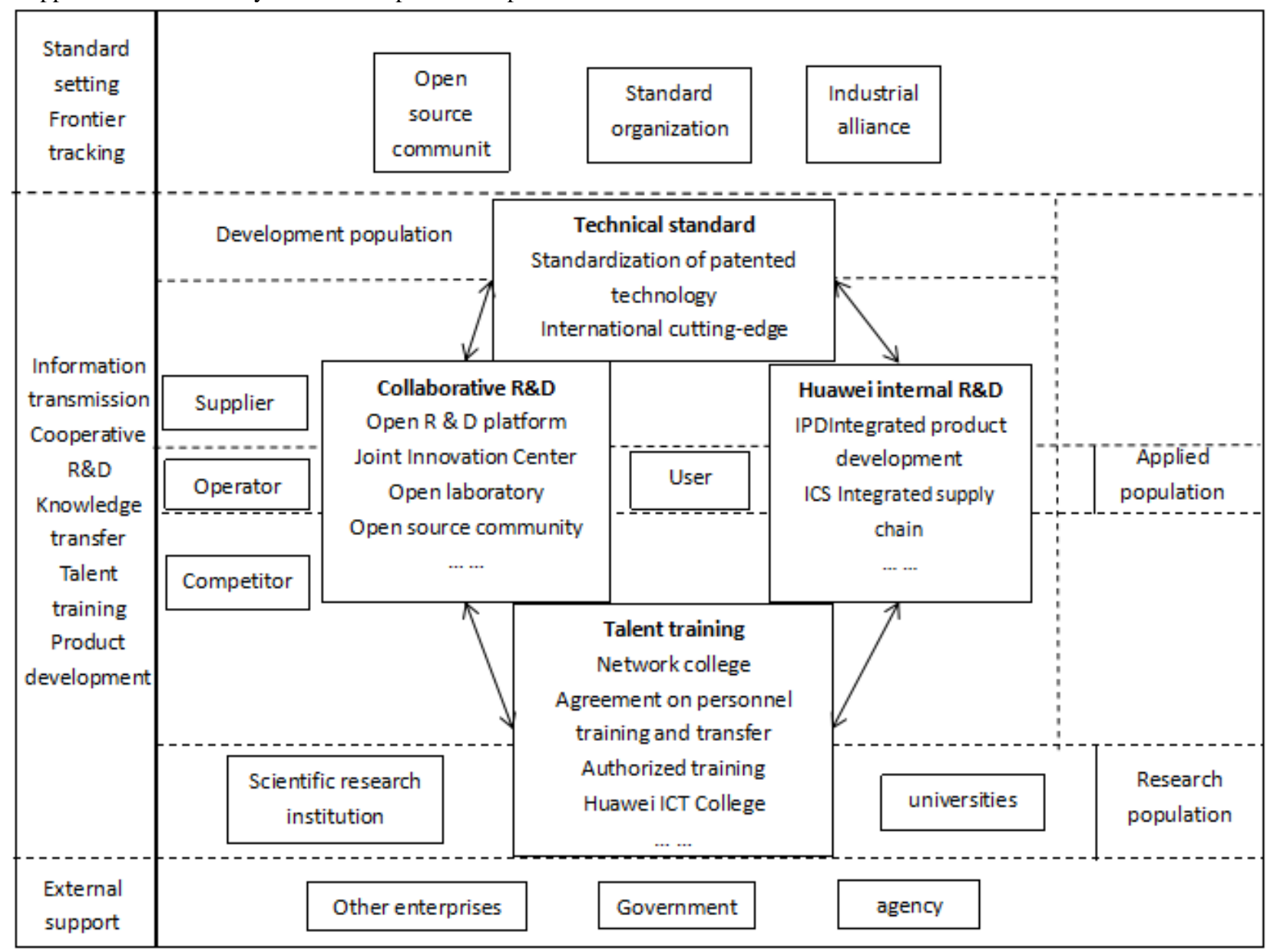

Figure 7 Innovation ecosystem in core technology breakthrough and rapid iteration phase of Huawei

At this stage, Huawei finally established a competitioncooperation symbiosis relationship dominated by cooperation with similar units, supplemented by competition, and a competition-cooperation symbiosis relationship with different units, and adopted a competition-cooperation symbiosis mechanism based on the symbiosis mode of resource sharing, resource separation and resource overlap (figure 8).

The open and sharing mechanism of Huawei innovation ecosystem attracts more innovation subjects to participate in Huawei's open innovation platform, establishes a more diverse sharing platform, and establishes closer and extensive ties with various subjects (figure 8). At this stage, Huawei has established cooperative relations with more enterprises, established a more favorable environment for innovation, joined a number of standards organizations, industrial alliances and open source communities, and gained a certain position among them. it provides great convenience for Huawei to obtain knowledge and technology information and to patent and 
standardize innovation achievements. Through the establishment of open source community and terminal developer alliance, users' participation in product development is increasing, which provides a lot of innovative inspiration and suggestions for Huawei baseband product iteration. Through the establishment of ICT College, we have established cooperative relations with many domestic universities, providing Huawei with a wealth of innovative talents.

At this stage, Huawei's competition and symbiosis mechanism adds a new component-open source community, and the relationship with similar units turns to cooperation-based and competition-supplemented development relationship. The cooperation between Huawei and heterogeneous units has made great progress, establishing more forms of competition and cooperation symbiosis interface, such as open source community, ICT Academy, etc., the interaction between each interface has become very frequent and close, forming a complex competition and cooperation symbiosis network.

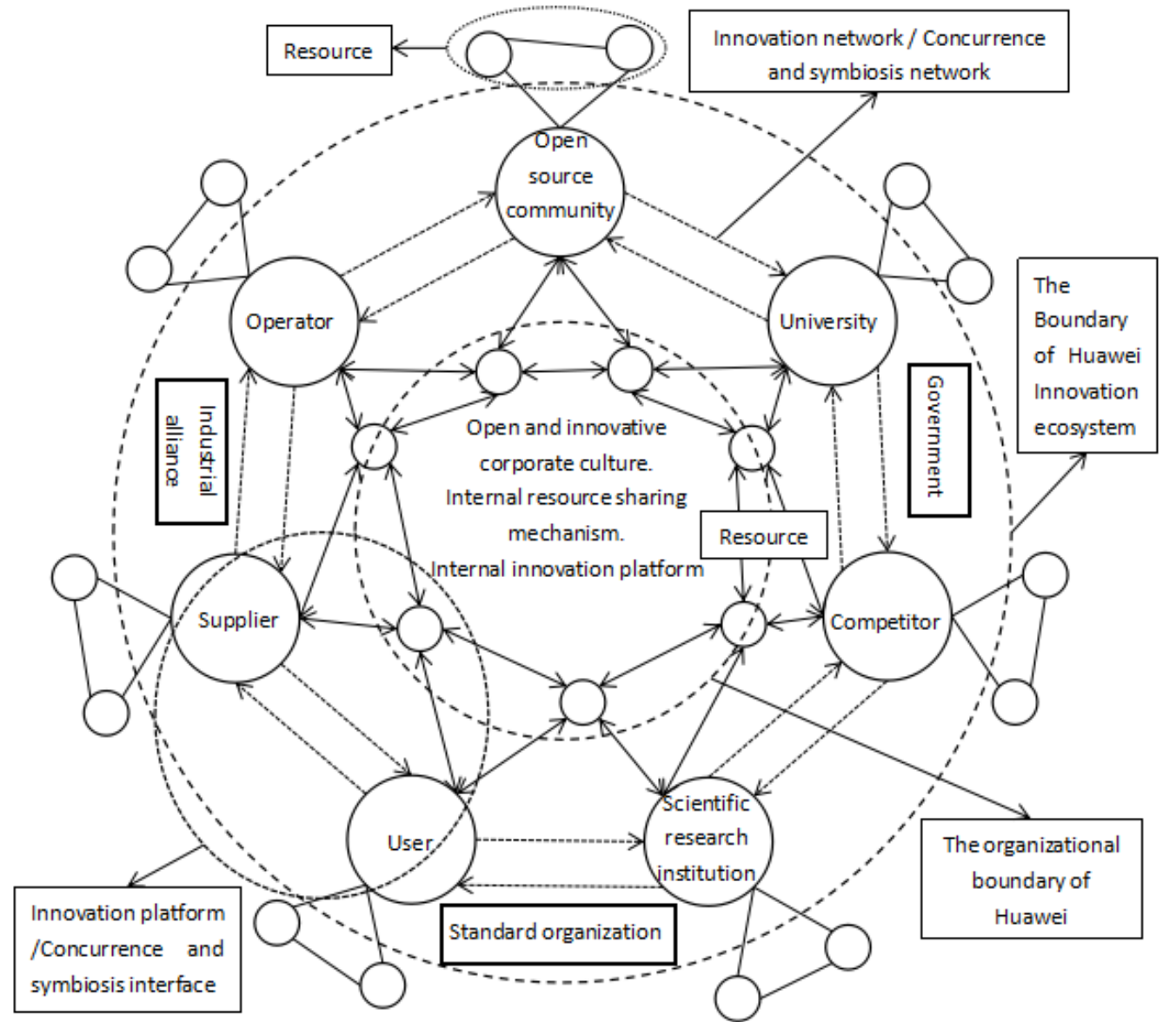

Figure 8 operating mechanism of innovation ecosystem in core technology breakthrough and rapid iteration phase of Huawei

At this stage, Huawei officially began the product research and development of baseband chip, relying on a large number of innovative resources and inspiration provided by Huawei's innovation ecosystem, coupled with efficient R \& D efficiency and harmonious development environment, successfully developed Huawei's first baseband chip product Barone 700, and completed a product integration breakthrough. Subsequently, the product iteration was carried out at a very fast speed to improve the performance of the baseband chip, and a series of products such as Barone and Kirin were released successively, which finally made Huawei's baseband products among the forefront of the world.

To sum up, the relevant contents of the above three stages can be summarized in Table 2.

Table 2 Huawei Baseband Chip Technology Breakthrough Mechanism from the Perspective of Innovation ecosystem

\begin{tabular}{|c|c|c|c|}
\hline $\begin{array}{c}\text { Time } \\
\text { Content }\end{array}$ & $\begin{array}{c}\text { Improve the internal R \& D } \\
\text { system ( 1987-1998 ) }\end{array}$ & $\begin{array}{c}\text { International R \& D layout } \\
\text { Core Technology Breakthrough } \\
\text { and Fast iteration ( 2007-2019) }\end{array}$ \\
\hline
\end{tabular}




\begin{tabular}{|c|c|c|c|}
\hline $\begin{array}{l}\text { Core } \\
\text { technology } \\
\text { breakthrough } \\
\text { stage }\end{array}$ & $\begin{array}{l}\text { General non-core } \\
\text { component technology } \\
\text { breakthrough }\end{array}$ & $\begin{array}{l}\text { General Core component } \\
\text { Technology Breakthrough }\end{array}$ & $\begin{array}{c}\text { Product integration and } \\
\text { optimization }\end{array}$ \\
\hline $\begin{array}{l}\text { Composition } \\
\text { of innovation } \\
\text { ecosystem }\end{array}$ & $\begin{array}{c}\text { Huawei, Cooperative } \\
\text { enterprise, joint ventures, } \\
\text { scientific research } \\
\text { institutions, universities, } \\
\text { customers }\end{array}$ & $\begin{array}{l}\text { Huawei, suppliers, operators, } \\
\text { universities, competitors, } \\
\text { scientific research institutions, } \\
\text { government, users, standards } \\
\text { organizations, industrial } \\
\text { alliances }\end{array}$ & $\begin{array}{l}\text { Huawei, suppliers, competitors, } \\
\text { operators, other enterprises, } \\
\text { universities, scientific research } \\
\text { institutions, governments, users, } \\
\text { industry alliances, standards } \\
\text { organizations, open source } \\
\text { communities, intermediaries }\end{array}$ \\
\hline $\begin{array}{l}\text { Innovate the } \\
\text { operating } \\
\text { mechanism of } \\
\text { ecosystem }\end{array}$ & $\begin{array}{l}\text { The opening and sharing } \\
\text { mechanism in which } \\
\text { intellectual property } \\
\text { management system, open } \\
\text { innovation culture and open } \\
\text { innovation platform } \\
\text { promote and coordinate } \\
\text { each other; competition and } \\
\text { cooperation symbiosis } \\
\text { mechanism based on } \\
\text { competition and } \\
\text { cooperation symbiosis } \\
\text { platform }\end{array}$ & $\begin{array}{l}\text { Internal open innovation } \\
\text { corporate culture, internal } \\
\text { resource sharing mechanism, } \\
\text { opening and sharing mechanism } \\
\text { that internal innovation platform } \\
\text { and open innovation platform } \\
\text { promote each other; competition } \\
\text { and cooperation symbiosis } \\
\text { mechanism based on } \\
\text { competition and cooperation } \\
\text { symbiosis interface }\end{array}$ & $\begin{array}{l}\text { The opening and sharing } \\
\text { mechanism with a wider range of } \\
\text { innovation subjects, more diverse } \\
\text { open innovation platforms, and } \\
\text { more closely related subjects; the } \\
\text { competition-cooperation } \\
\text { symbiosis mechanism based on } \\
\text { competition-cooperation } \\
\text { symbiosis network }\end{array}$ \\
\hline $\begin{array}{l}\text { Core } \\
\text { technology } \\
\text { progress }\end{array}$ & $\begin{array}{l}\text { It has the technology of } \\
\text { voice codec, clock } \\
\text { synchronization, interface, } \\
\text { integrated circuit and so on }\end{array}$ & $\begin{array}{l}\text { All technologies have } \\
\text { completed functional } \\
\text { breakthroughs and performance } \\
\text { optimization }\end{array}$ & $\begin{array}{c}\text { Successful completion of product } \\
\text { integration breakthrough and } \\
\text { product iteration }\end{array}$ \\
\hline
\end{tabular}

\section{CONCLUSION AND ENLIGHTENMENT}

\subsection{Conclusion}

(1) Through its operating mechanisms such as opening and sharing, competition and symbiosis, the innovation ecosystem supports innovation resources, accelerates the flow of innovation resources, optimizes the innovation development environment, and reduces the risk and cost of $\mathrm{R} \& \mathrm{D}$. Promote the core technology breakthrough of enterprises, such as improving $\mathrm{R} \& \mathrm{D}$ efficiency. The internal opening and sharing mechanism of Huawei provides a solid foundation for the operation of Huawei's innovation platform, while the external opening and sharing mechanism establishes long-term communication and cooperation with various innovative subjects by constructing an external open innovation platform. it provides sufficient innovation resources to support Huawei's baseband chip technology breakthrough and reduces the risk and cost of Huawei's research and development. In addition, through the establishment and operation of the innovation platform and the competitive and cooperative symbiosis platform, the subjects become a community of interests, reduce unnecessary competition, and build a harmonious external environment for Huawei's innovation and development.

(2) The breakthrough of Huawei baseband chip technology has gone through three stages: general non-core component technology breakthrough, general core component technology breakthrough and product integration and optimization. The breakthrough of general non-core component technology is to master the basic knowledge and technology needed to learn or innovate other technologies in the components that complete noncore functions in the core technology components, or to learn or innovate other technologies in the components that complete the non-core functions in the core 
technology components. The breakthrough of general core component technology is to master the technology that crosses with the technologies needed by other business in the components that complete the core functions in the core technology components. Product integration and optimization is to combine all the technologies contained in the core technology, integrate on the same product and optimize the product performance.

\subsection{Theoretical contribution}

(1) The innovation ecosystem theory is used to expand the research perspective and theoretical choice of enterprise core technology breakthrough. The existing researches mainly study the core technological breakthroughs of enterprises from the theoretical perspectives of innovation catch-up, capability, network and evolution, and few studies discuss the role of innovation ecosystem in the process of core technological breakthroughs of enterprises from the perspective of innovation ecosystem theory. This study examines the whole process of Huawei baseband chip technology breakthrough from the perspective of innovation ecosystem. It provides an explanation in the context of innovation ecosystem for enterprise core technology breakthrough, and expands the research perspective and theoretical choice of enterprise core technology breakthrough.

(2) The analytical framework of enterprise core technological breakthrough from the perspective of innovation ecosystem is established (figure 9). Through the comprehensive use of innovation ecosystem and core technology theory, this paper tentatively establishes the analytical framework of enterprise core technology breakthrough from the perspective of innovation ecosystem, and defines the main body, elements, operating mechanism and breakthrough process. This paper discusses how the innovation ecosystem provides support for the breakthrough of enterprise core technology through its operating mechanism, and provides concrete guidance for the analysis of the breakthrough path of enterprise core technology.

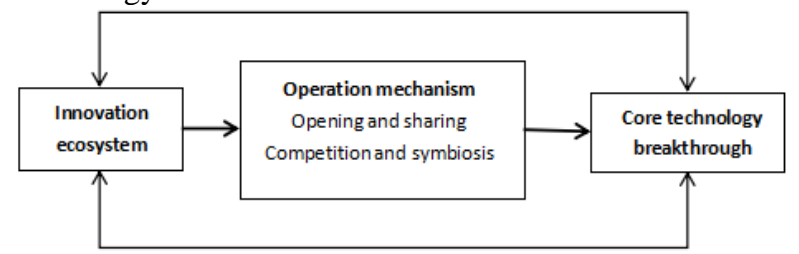

Figure 9 Analytical framework

\subsection{Practical enlightenment}

(1) To provide countermeasures and guidance for enterprises to make core technological breakthroughs. When an enterprise makes a breakthrough in the core technology, it can make a breakthrough in turn according to its constituent technology, and it can also enhance the economic value of the technology in the $\mathrm{R} \& \mathrm{D}$ stage according to the degree of intersection between it and the existing business of the enterprise. When enterprises make core technological breakthroughs, it is difficult for individual enterprises to support and obtain all the resources needed for core technological breakthroughs, so they can adopt open innovation strategies, join or establish innovation ecosystems, and obtain innovation resources in the innovation platform. to provide support for the enterprise's core technology breakthrough, but also can reduce the risk of research and development, and provide a good environment for enterprise innovation and development.

(2) Provide guidance for other participants in the innovation ecosystem. Through the analysis of Huawei enterprise innovation ecosystem, different innovation subjects play different roles in different stages of the innovation ecosystem, have their own division of labor, and have different available resources. According to the analysis of the operation mechanism of the innovation ecosystem in different stages, it is helpful for the relevant subjects to grasp their own role and role in the innovation ecosystem, and to provide guidance for enterprises to adopt what kind of innovation and management strategies are conducive to the breakthrough of their core technologies at different stages of development.

\subsection{Practical enlightenment}

The data sources of this study are mainly second-hand data, and the limitation of data is one of the limitations of this study. In addition, the discussion on the operation mechanism of innovation ecosystem is mainly based on opening and sharing mechanism, competition and symbiosis mechanism, and how to promote enterprise core technology breakthrough through its operation mechanism remains to be improved. At the same time, because the core technology of each industry and product is different, and the structure of each core technology is also different, the core technology breakthrough of enterprises must adapt to their own situation. Therefore, this study has limitations to explore the path of core technology breakthrough in various industries. In order to improve the universality of the research, future research can use a variety of data sources, select enterprise cases in different industries, explore the internal mechanism of innovation ecosystem to promote core technological breakthroughs, and establish a more perfect analysis framework.

\section{ACKNOWLEDGMENT}

This work was supported by National Natural Science Foundation of China (71772161) and the key soft Science Research Project of Zhejiang Province (2019C25021). 


\section{REFERENCES}

[1]R.Adner, Match your Innovation Strategy to your Innovation Ecosystem, in: J. Harvard Business Review. 84 $\begin{array}{llll} & (2006) & 2-11 . & \text { DOI : }\end{array}$ https://doi.org/10.1177/1059601104273065

[2]Zhang Gui,Wen Ke,Song Xinping,et al.Innovation ecosystem: theory and practice, in: M. Beijing: economiy \& Management Publishing House,2018

[3]Zhang Yunsheng, Research on risk Identification and Control of High-tech Enterprise Innovation ecosystem, in: J. The Theory and Practice of Finance and Economics. 29(3) (2008) 113-116. DOI : https://doi.org/10.3969/j.issn.1003-7217.2008.03.024

[4]Li Wan,Chang Jing,Wang Minjie,Zhu Xueyan,Jin Aimin, Innovation 3.0 and Innovation ecosystem, in: J - Studies in Science of Science. 32(12) (2014) 1761-1770 DOI : https://doi.org/10.16192/j.cnki.10032053.2014.12.001

[5]Mei Liang,Chen Jin,Liu Yang, Innovation ecosystem: Origin, knowledge Evolution and theoretical Framework, in: J. Studies in Science of Science. 32(12) (2014) 17711780 . DOI : https://doi.org/10.16192/j.cnki.10032053.2014.12.002

[6]S. Zahra,S. Nambisa, Entrepreneurship and strategic thinking in business ecosystems, in: J. Business Horizons. 55(3) (2012) 219-229 . DOI : https://doi.org/10.1016/j.bushor.2011.12.004

[7]D.S. Oh,F. Phillips,S. Park,E. Lee, Innovation ecosystems: A critical examination,in: J.Technovation. 54(8) (2016) 1-6. DOI:

https://doi.org/10.1016/j.technovation.2016.02.004

[8]E. Judy, Is American innovation declining? in: M . Beijing: China Machine Press, 2010.

[9]Zhao Guangfeng,ma Zhiqiang,Zhu Yongyue, Construction and Operation Mechanism of Innovation ecosystem in Colleges and Universities[J].Forum on Science and Technology in China. (01) (2017) 40-46. DOI : https://doi.org/10.13580/j.cnki.fstc.2017.01.007

[10]Liang Haishan,Wei Jiang,Wan Xinming, The change of Enterprise technological Innovation capability system and its performance influence Mechanism-- Haier Open Innovation New Paradigm,in: J. Management Review. 30(7) (2018) 281-291. DOI : https://doi.org/10.14120/j.cnki.cn11-5057/f.2018.07.025

[11]Chen Lu,Wu Jie,Sheng Yongxiang,Liu Peng,Shi Qinfen, Research on the relationship of Multi-agent Competition and Cooperation in Patent Innovation ecosystem,in: J. Journal of Information. 36(12) (2017) 82-
89. DOI : https://doi.org/CNKI:SUN:QBZZ.0.2017-12015

[12]Ou Zhonghui,Zhu Zuping,Xia Min,Chen Yantai, Symbiotic Evolution Model and Simulation of Innovation ecosystem,in: J. Science Research Management. 38(12) (2017) 49-57. DOI https://doi.org/CNKI:SUN:KYGL.0.2017-12-006

[13]Wu Shaobo,Gu Xin,Wu Guangdong,Gong Ying, Technological Learning of Innovation ecosystem in emerging Industries,in: J. Forum on Science and Technology in China. (07) (2016) 30-35+42.DOI : https://doi.org/10.13580/j.cnki.fstc.2016.07.005

[14]Liu Chang,Li Jianhua., On Collaborative Innovation Mechanism of Quadruple Spiral Innovation ecosystem,in: J. Economic Review Journal. (3) (2019) 126-132. DOI: https://doi.org/10.16528/j.cnki.22-1054/f.201903122

[15]Sun Cong,Wei Jiang, Research on the structure and Collaborative Mechanism of Enterprise-level Innovation ecosystem,in: J. Studies in Science of Science. 37(07) (2019) 1316-13 $25 . \quad$ DOI : https://doi.org/10.16192/j.cnki.1003-2053.2019.07.018

[16]Zhang Gui,Zhang Jiali, Catalysis and emergence: a New Exploration of Industrial Innovation Model,in: J. Science \& Technology Progress and Policy. (17) (2012) 56-60. DOI: https://doi.org/10.6049/kjjbydc.2011100458

[17]H. Chesbrough, Open Innovation, the New Imperative for Creating and Profiting from Technology,in: M. Boston:Harvard Business School Press,2003.

[18]Hong Chuang,Li he,Zhu Linlin,Zhang Keyong, Review and Prospect of Open Innovation Research in China,in: J. Journal of Modern Information,38(06) (2018) 165-171+177. DOI https://doi.org/CNKI:SUN:XDQB.0.2018-06-024

[19]Liu Wentao, The Challenge of technological Innovation in the Open Innovation Environment,in: J. Science and Technology Management Research. (3) (2012) $12-14$, 54. DOI : https://doi.org/10.3969/j.issn.10007695.2012.03.004

[20]Sun Hai,Xu Zhengquan, The path of Open Innovation to promote Independent Innovation-- A case study based on Coal-to-Oil Technology Innovation,in: J. Science \& Technology and Economy. (1) (2009) $7-10$. DOI : https://doi.org/10.3969/j.issn.1003-7691.2009.01.002

[21]Huang Jiangming,Ding Ling,Cui Zhengyan, Enterprise niche builds competitive advantage of Business Ecology: a case comparison between Yutong and BAIC,in: J. Management Review. (5) (2016) 220-231.

[22]J. Ehrenfeld, Industrial Ecology:A New Field or Only a Metaphor?,in: J. Journal of Cleaner Production. 12(8) 
(2004)

$825-831$.

DOI

https://doi.org/10.1016/j.jclepro.2004.02.003

[23] Hu Xiaopeng, Industrial Symbiosis: theoretical definition and its Internal Mechanism,in: J. China Industrial Economics. (9) (2008) 118-128. DOI : https://doi.org/10.19581/j.cnki.ciejournal.2008.09.012

[24]D.G. Kopp,R.J. Litschert, A buffering response in light of variation in core technology, perceived environmental uncertainty, and size,in: J. The Academy of Management Journal. 23(2) (1980) 252-266. DOI:

https://doi.org/10.2307/255430

[25]E.G. Carayannis,E.M. Rogers,K. Kurihara,M.M. Allbritton, High technology spin-offs from government R\&D laboratories and research universities,in: J. Technovation. 18 (1) (1998) 1-11. DOI : https://doi.org/10.1016/S0166-4972(97)00101-6

[26]Ma Junru, Core Technology and Core Competitiveness-- discussion on the combination of Industry, University and Research with Enterprises as the Core,in: J. China Soft Science. (7) (2005) 4-6. DOI: https://doi.org/10.3969/j.issn.1002-9753.2005.07.002

[27]Wang Jiang, On the importance of Enterprise Core Technology from the Perspective of "DVD Patent event",in: J. Journal of Northeastern University ( Social Science ) . (1) (2003) 34 - 36. DOI : https://doi.org/CNKI:SUN:DBDS.0.2003-01-012

[28]Gao Qiaozi, Analysis and Countermeasure Research on the deficiency of Core Technology of Chinese Enterprises,in: J. Tribune of Study. (3) (2018) 54-58. DOI: https://doi.org/10.16133/j.cnki.xxlt.2018.03.009

[29]Jia Xiang,Luo Yanglong, First of all, the core competitiveness of independent brands is the core technology: an interview with $\mathrm{Fu} \mathrm{Yuwu,} \mathrm{vice} \mathrm{president}$ and secretary-general of the Chinese Society of Automotive Engineering,in: J. Auto Review. (3) (2012) $17-20$.

[30]Hong Yong,Su Jingqin, Research on the coordinated Development of Core Industry chain and Core Technology chain in developing countries,in: J. China Industrial Economics. (6) (2007) 38-45. DOI : https://doi.org/10.19581/j.cnki.ciejournal.2007.06.005

[31]Li Xianjun,Meng Donghui,Liu Jie, Microcosmic Mechanism and Breakthrough path of Core Technology-taking Chinese Automobile AMT Technology as an example,in: J. Chinese Soft Science. (08) (2018) 88-104. DOI: https://doi.org/ CNKI:SUN:ZGRK.0.2018-08-009

[32]Guo Lei, Cai Hong, Xu Luying, Dual Technology catch-up performance of late-developing Enterprises in the transition stage-- from the Perspective of Patent,in: J. Science and Technology Management Research. 36(11)
(2016)

139-144+155.DOI

https://doi.org/10.3969/j.issn.1000-7695.2016.11.026

[33]Zhu Ruibo,Liu Zhiyang,Liu Yun, Structural Innovation, niche Optimization and Leap-forward catch-up of late-developing Enterprises-- A theoretical Exploration based on the Innovation practice of BYD, MediaTek, Huawei and Zhenhua heavy Industry,in: J. Management World. (07) (2011) 69-97+188. DOI : https://doi.org/10.19744/j.cnki.11-1235/f.2011.07.008

[34]Gu Liangfeng, Xu Qingrui, Product Modularization and Strategic Management of Enterprise Technology and its Innovation,in: J. R\&D Management. (02) (2006) 7-14. DOI: https://doi.org/10.13581/j.cnki.rdm.2006.02.002

[35]Zhang Mir,Tian Dan, Research on the formation of Enterprise Core technological competence based on niche Strategy,in: J. Studies in Science of Science. (03) (2005) 388-393. DOI : https://doi.org/10.16192/j.cnki.10032053.2005.03.019

[36]Meng Donghui,Li Xianjun,Mei Liang, Qi Xingda, Deconstruction and Breakthrough of Core Technology: a Longitudinal case study of "Tsinghua-Green Control" AMT Technology from 2000 to 2016,in: J. Science Research Management. 39(6) (2018) 75-84. DOI : https://doi.org/10.19571/j.cnki.1000-2995.2018.06.009

[37]K.M. Eisenhardt.Building Theories from Case Study Research,in: J. The Academy of Management Review. 14(4) (1989) 532-550. DOI : https://doi.org/10.5465/AMR.1989.4308385

[38]K.M. Eisenhardt,M.E. Graebner, Theory building from cases: Opportunities and challenges,in: J. Academy of Management Journal. 50(1) (2007) 25-32. DOI:

https://doi.org/10.5465/AMJ.2007.24160888

[39]S.K. Ethiraj, Allocation of inventive effort in complex product systems,in: J. Strategic Management Journal. 28(6) (2007) 563-584. DOI:

https://doi.org/10.1002/smj.622

[40]Ouyang Taohua,Hu Jingbo,Li Yang,Zhou Ning,Guo Hui, Research on the dynamic Evolution of DFH small Satellite complex Product Innovation ecosystem: from the Perspective of Strategic Logic and organizational Cooperation adaptation,in: J. Chinese Journal of Management. 12(04) (2015) 546-557. DOI : https://doi.org/10.3969/j.issn.1672-884x.2015.04.010

[41]A. Langley,C. Smallman,H. Tsoukas,et al. Process studies of change in organization and management: Unveiling temporality, activity and flow,in: J. Academy of Management Journal. 56(1) (2013) 1-13. DOI:

https://doi.org/10.5465/amj.2013.4001 
[42]Zheng Shaofang,Tang Fangcheng, Knowledge Governance Mechanism of Innovation ecosystem in Hightech Enterprises,in: J. Forum on Science and Technology in China. (1) (2018) 47-57. DOI : https://doi.org/10.13580/j.cnki.fstc.2018.01.008

[43]Jiang Sanliang,Chen Rui, Research on Innovation and Enterprise growth from the Perspective of supply side-- A case study of Huawei Company,in: J. Journal of Commercial Economics. (15) (2017) 103-105. DOI : https://doi.org/10.3969/j.issn.1002-5863.2017.15.037

[44]Su Jingqin,Liu Jing, Case study Research on the Reliability of second-hand data from the Perspective of Standardization,in: J. Chinese Journal of Management. (10) (2013) 1405-1409, 1418. DOI : https://doi.org/10.3969/j.issn.1672-884x.2013.10.001

[45]Pan Yingjin.Research on Baseband Chip Architecture and Verification,in: J. Electronics World. (5) (2016) 179180. DOI

https://doi.org/10.19353/j.cnki.dzsj.2016.05.077

[46]Si Hui, Research and Development and Innovation of Huawei,in: M. Shenzhen: Haitian Publishing House, 2012.

[47]Wu Xiaobo,P.M. John,Huang can,et al.Huawei Management Reform,in: M. Beijing:Citic Press Group, 2017.

[48]Liu Wendong, The internationalization of Huawei,in: M. Shenzhen: Haitian Publishing House, 2010

[49]Sun Keliu,Yi Shengjun,Chen Linkong, Huawei, you can't learn,in: M. Beijing:China Renmin University Press , 2016

[50]Yin Zhixin, Yuan Like,Li Zhenxing, Global Innovation layout and Mode Choice of High-tech Enterprises-- taking Huawei as an example,in: J. Forum on Science and Technology in China. (10) (2017) 72-79. DOI : https://doi.org/10.13580/j.cnki.fstc.2017.10.008

[51]Liu Pingqing,Wu Anze, Understanding and thinking on the Innovation and Development of Huawei Enterprises,in: J. Management World. 34(12) (2018) 188189. DOI : https://doi.org/10.19744/j.cnki.111235/f.2018.0051

[52]Xu Yusen,Zheng Shupeng,Li Jinru, Research on the Co-performance process of International Interface, Resource system and technological Innovation,in: J. Studies in Science of Science. 36(11) (2018) 2092-2102. DOI : $\quad$ https://doi.org/10.16192/j.cnki.10032053.2018.11.019

[53]Liu Xielin,Wu Sheng,Juli, Huawei's overseas R \& D activity Development and Global R \& D Network Analysis,in: J. Studies in Science of Science. 35 (06) $\begin{array}{lcc}(2017) & 834-841+862 & \text { DOI }\end{array}$ :

[54]N. Siggelkow, Firms as systems of interdependent choices,in: J. Journal of Management Studies. 48(5) (2011) 1126-1140. DOI:

https://doi.org/10.1111/j.1467-6486.2011.01010.x

[55]Chen Jin, On the enterprise innovation ecosystem.,in: M. Beijing:Science Press, 2017

[56]H.E. von, Democratizing innovation :the evolving phenomenon of user innovation,in: J. Journal für Betriebswirtschaft. 55(1) (2005) 63-78. DOI : https://doi.org/10.1007/s11301-004-0002-8

[57]H. Etzkowitz,L. Leydesdorff, The dynamics of innovation:from national systems and "Mode 2"to a triple Helix of university-industry-government relations,in: J. Research Policy. 29(2) (2000) 109-123. DOI:

https://doi.org/10.1016/S0048-7333(99)00055-4

[58]J.H. Dyer, Specialized supplier networks as a source of competitive advantage:evidence from the auto industry,in: J. Strategic Management Journal. 17(4) (1996) 271-291. DOI:

https://doi.org/10.1002/(SICI)10970266(199604)17:4<271::AID-SMJ807>3.0.CO;2-Y

[59]L. Argote,B. McEvily,R. Reagans, Managing knowledge in organizations:an integrative framework and review of emerging themes,in: J. Management Science. 49(4) (2003) 571-582. DOI:

https://doi.org/10.1287/mnsc.49.4.571.14424

[60]Chen Jin, Collaborative Innovation and the Construction of National Scientific Research capacity,in: J. Studies in Science of Science. 29(2) (2011) 2-3. DOI: https://doi.org/10.16192/j.cnki.1003-2053.2011.12.019

[61]He Yubing, The theoretical model of industryuniversity-research collaborative innovation,in: J. Studies in Science of Science. 30(2) (2012) 165-174. DOI : https://doi.org/10.16192/j.cnki.1003-2053.2012.02.002 